\title{
Awareness of Herpangina and its Managements Among Dental Students
}

\author{
Reshma Thirunavakarasu', Dhanraj Ganapathy ${ }^{2}$ and Subhashree R ${ }^{3}$ \\ ${ }^{1}$ Reshma Thirunavakarasu Saveetha Dental College and Hospitals, Saveetha Institute \\ of Medical and Technical Science Saveetha University, Chennai 77, India \\ ${ }^{2}$ Professor and Head of Department Department of Prosthodontics Saveetha Dental College and Hospitals, \\ Saveetha Institute of Medical and Technical Science Saveetha University, Chennai 77, India \\ ${ }^{3}$ Senior Lecturer, Department of Prosthodontics Saveetha Dental College and Hospitals, Saveetha \\ Institute of Medical and Technical Science Saveetha University, Chennai 77, India
}

\section{ABSTRACT}

Herpangina or otherwise known as hand-foot and mouth disease (HMFD) is caused by enteroviral infection and are two common related clinical syndromes. These diseases are mostly seen in paediatric population ( 7 to 10 years). It is occasionally seen among adult patients. Herpangina is caused by one particular strain of coxsackievirus A (CV-A) and Enterovirus -A71 (EV-A71). Herpangina is an acute upper respiratory tract infection. A survey with 9 close ended questions and 3 multiple choice questions were formed and distributed to dental students These responses to these questions were tabulated then analyzed and studied. The study showed that $86 \%$ of the students are aware of the disease herpangina. $57 \%$ of the students were not aware of the other name of herpangina. $89 \%$ of the students were aware that herpangina is a contagious disease and that it is a viral infection.The overall awareness and knowledge level of the students were good however further knowledge and awareness can be emphasized. Awareness of dental students can always be enhanced by promoting more educational programmes regarding various diseases such as herpangina. It is important as they will play an important role in the medical field in the future.

KEY WORDS: AWARENESS, DENTAL STUDENTS, HERPANGINA.

\section{INTRODUCTION}

Herpangina or otherwise known as hand-foot and mouth disease (HMFD) is caused by enteroviral infection and are two common related clinical syndromes. These diseases are mostly seen in paediatric population (7 to 10 years).

\section{ARTICLE INFORMATION}

*Corresponding Author: dhanraj@saveetha.com

Received 23rd June 2020 Accepted after revision 8th August 2020

Print ISSN: 0974-6455 Online ISSN: 2321-4007 CODEN: BBRCBA

Thomson Reuters ISI Web of Science Clarivate Analytics USA and Crossref Indexed Journal

\section{Clarivate
Analytics}

NAAS Journal Score 2020 (4.31) SJIF: 2020 (7.728)

A Society of Science and Nature Publication,

Bhopal India 2020. All rights reserved.

Online Contents Available at: http//www.bbrc.in/

Doi: $h t t p: / / d x . d o i . o r g / 10.21786 / b b r c / 13.7 / 9$
It is occasionally seen among adult patients (Corsino and Linklater, 2019) Herpangina is caused by one particular strain of coxsackievirus A (CV-A) and Enterovirus -A71 (EV-A71). Herpangina is an acute upper respiratory tract infection . It was found that patients/ individuals with latent infections are the ones who can easily spread the infection (Li et al., 2018; Yu et al., 2020) Typical spread of this disease is via fecal-oral route. Transmission can be from the ingestion of infected saliva, respiratory droplets or direct contact with fluid from vesicles. Incubation period of 3-5 days. (Repass, Palmer and Stancampiano, 2014; Corsino and Linklater, 2019)

There are various clinical manifestations to this disease. Herpangina is an acute disease which is characterised by a sudden onset of fever and sore throat followed by

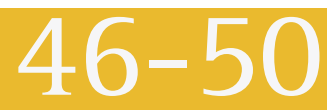


fever which may last up to 2-4 days. Cough, rhinorrhoea, vomiting, diarrhoea and sometimes headache, abdominal pain or myalgia and dysphagia in severe sore throat cases can be seen (Yu et al., 2020) Skin eruptions is manifested as papules or vesicles or petechiae on the hand and/or feet or as aphthae on the tongue and oral mucosa.(Wang et al., 1999; Wang and Liu, 2009) There are various oral manifestations as well to this disease such as vesicles, ulceration and diffuse erythema on the soft palate, fauces and tonsillar area(Van Heerden, 2006) Various differential diagnosis can be given to this disease such as herpetic gingivostomatitis, ulcerative stomatitis, measles and varicella. (Yu et al., 2020)

Table 1. Closed ended questions

\begin{tabular}{|c|c|c|c|}
\hline 1. & $\begin{array}{c}\text { Are you aware of the disease } \\
\text { known as herpangina? }\end{array}$ & Yes & No \\
\hline 2. & Are you aware of its other name? & Yes & No \\
\hline 3. & Is herpangina contagious? & Yes & No \\
\hline 4. & Is herpangina a viral infection? & Yes & No \\
\hline 5. & Is there antiviral therapy for herpangina? & Yes & No \\
\hline 6. & Can herpangina be prevented? & Yes & No \\
\hline 7. & $\begin{array}{c}\text { Does herpangina cause } \\
\text { any signs in the oral cavity? }\end{array}$ & Yes & No \\
\hline 8. & $\begin{array}{c}\text { Will mouthwashes help control } \\
\text { mouth pain in a herpangina patient? }\end{array}$ & Yes & No \\
\hline 9. & Will a change of diet aid in treatment? & Yes & No \\
\hline
\end{tabular}

The only treatment available for this disease is primary supportive treatments. There is no prophylaxis for herpangina or HFMD (Corsino and Linklater, 2019)) Since herpangina and HFMD disease are self-limiting or short duration and do not require treatment. Symptomatic treatment is indicated in very severe cases of herpangina in which non-aspirin antipyretics and topical anaesthetics can be used. (Van Heerden, 2006) Lidocaine or topical therapies are not recommended due the risks for toxicity associated with these medications. The use of intravenous immunoglobulin (IVIG) in Asia to treat patients with herpangina has shown major outbreaks however it has no prospective data collected about the use of this drug. (Chea et al., 2015; Corsino and Linklater, 2019; Jiao et al., 2019) The aim of this study is to determine if dental students are aware of the various managements done for herpangina.

Previously our department has published extensive research on various aspects of prosthetic dentistry ('Evaluation of Corrosive Behavior of Four Nickelchromium Alloys in Artificial Saliva by Cyclic Polarization Test:An in vitro Study', 2017; Ganapathy, Kannan and Venugopalan, 2017; Jain, 2017a, 2017b; Ranganathan, Ganapathy and Jain, 2017; Ariga et al., 2018; Gupta, Ariga and Deogade, 2018; Anbu et al., 2019; Ashok and Ganapathy, 2019; Duraisamy et al., 2019; Varghese, Ramesh and Veeraiyan, 2019), this vast research experience has inspired us to research about the level of awareness herpangina and its managements among dental students

\section{MATERIAL AND METHODS}

A survey with 9 close ended questions and 3 multiple choice questions were formed and distributed to dental students (3rd Yrs, 4th Yrs and Interns) as shown in Table 1 and Table 2 respectively. These responses to these questions were tabulated then analysed and studied. Their responses will determine the level of awareness of students regarding the management of herpangina.

\section{RESULTS AND DISCUSSION}

A total of 100 students have participated in this survey. The results were obtained and tabulated. Table and charts are done to depict clearly the level of knowledge the students have towards the disease as well as its management.

\begin{tabular}{|c|c|c|c|c|}
\hline Question: & A & B & C & $\mathrm{D}$ \\
\hline $\begin{array}{l}\text { 10. Which age group? } \\
\text { of people are } \\
\text { mostly affected }\end{array}$ & $3-10$ yrs & $11-19 y r s$ & 20-30yrs & $31-40 y r s$ \\
\hline $\begin{array}{l}\text { 11. Which organism } \\
\text { causes herpangina? }\end{array}$ & $\begin{array}{c}\text { Group A } \\
\text { coxsackie viruses }\end{array}$ & Staphylococcus & Streptococcus & \\
\hline $\begin{array}{l}\text { 12. What medications } \\
\text { are advised? }\end{array}$ & Antibiotics & antivirals & $\begin{array}{l}\text { No medications. } \\
\text { Only analgesics }\end{array}$ & \\
\hline
\end{tabular}

It was found that around 86\% of the students are aware of this disease. It is a very well-known disease and it was found that in 1998, an epidemic of EV71 infection caused HFMD and herpangina in thousands of people in Taiwan, including 405 severe cases and 78 deaths(July, 1998; Wang et al., 1999) Due to this epidemic, the existence of this disease was known by the population.
However, it was found that only 57\% of the students were aware that herpangina had another name. As we all know herpangina was also referred to as hand foot and mouth disease (HFMD). There is still some confusion among the students regarding this fact. It was found that only 55\% of the students have correctly identified that this disease mainly affects children, more accurately 
children lesser than 6 years old (Yu et al., 2020) There has been a case report of herpangina done in Nagpur, India which shows that a total of 4 cases were reported, ( 2 male and 2 female), all these patients had the classic clinical manifestation of oral and skin lesion. The age group of these patients were 3-4 year old children. (Saoji, 2008).

Table1a. Shows the level of knowledge and awareness of students regarding herpangina. $86 \%$ of the students are aware of the disease herpangina. 57\% of the students were not aware of the other name of herpangina. 89\% of the students were aware that herpangina is a contagious disease and that it is a viral infection. Only 53\% of the students were aware that there is no available antiviral therapy for herpangina. It was found that 93\% of the students were aware that herpangina can be prevented. $\mathbf{9 7 \%}$ of the students were aware that herpangina can produce signs in the oral cavity. 79\% of the students have knowledge that there are mouthwashes which will help control the mouth pain in herpangina patients. There were only $69 \%$ of the students that agreed that a change in diet can help in the treatment of herpangina.

\begin{tabular}{|l|c|c|}
\hline Questions & Yes & No \\
\hline $\begin{array}{l}\text { Are you aware of the } \\
\text { disease known as herpangina? }\end{array}$ & $86 \%$ & $14 \%$ \\
\hline Are you aware of its other name? & $43 \%$ & $57 \%$ \\
\hline Is herpangina contagious? & $89 \%$ & $11 \%$ \\
\hline Is herpangina a viral infection? & $89 \%$ & $11 \%$ \\
\hline Is there antiviral therapy for herpangina? & $47 \%$ & $53 \%$ \\
\hline Can herpangina be prevented? & $93 \%$ & $7 \%$ \\
\hline $\begin{array}{l}\text { Does herpangina cause any } \\
\text { signs in the oral cavity? }\end{array}$ & $97 \%$ & $3 \%$ \\
\hline Will mouthwashes help control & $79 \%$ & $21 \%$ \\
\hline $\begin{array}{l}\text { mouth pain in herpangina patient? } \\
\text { Will a change of diet aid in treatment ? }\end{array}$ & $69 \%$ & $31 \%$ \\
\hline
\end{tabular}

Figure 1: Pie chart shows the responses of students based on the most affected age group for herpangina. The highest response was 3-10yrs (55\%) and the remaining 45\% belongs to the remaining age groups. 11-19 years 20-30 years = 31-40 years
[-10 years

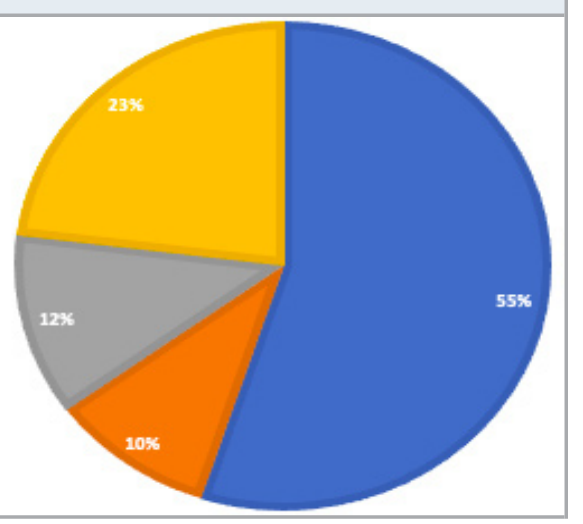

It was found that about $89 \%$ of the students are aware that herpangina is a viral infection and $89 \%$ of the students are aware that this disease can be contagious. Various articles have discussed that this disease is transmitted through the gastrointestinal tract (fecal-oral route) and respiratory route or through contact with an infected person.(Li et al., 2018; Yu et al., 2020) Knowledge regarding what type of infection it is should be known by the students so that they can take preventive measures as these dental students deal with patients day in and day out. $75 \%$ of the students have correctly identified the causative organism of this disease which is Group A coxsackieviruses. Knowledge regarding the causative organisms distinguished this disease from other diseases as well as it can help plan the future treatments needed to be taken.

Figure 2: Pie chart shows the responses of students for the causative organism of herpangina. $75 \%$ of the students selected group A coxsackieviruses.

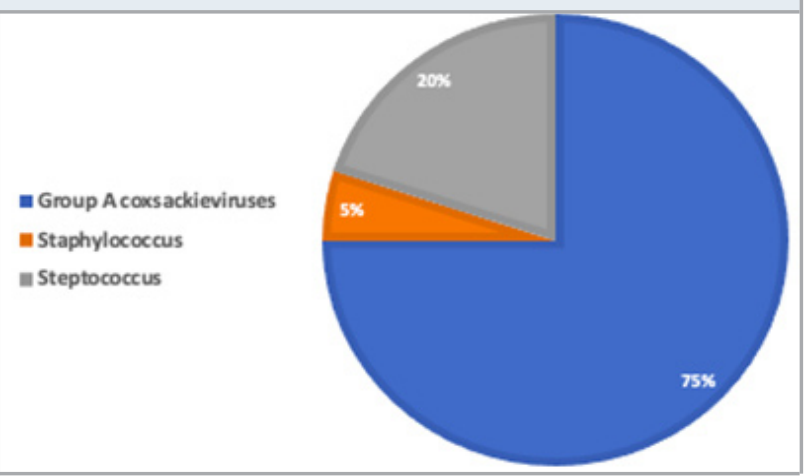

Herpangina can be prevented and about 93\% of the students were aware of this fact. A study was done and found that a strong protective effect of hand washing could be expected as the main transmission rate is by hand contact. (Ruan et al., 2011) As we know the transmission of herpangina is by ingestion of infected saliva, respiratory droplets or direct contact with fluid from vesicles. Thus importance regarding the knowledge on how to prevent this disease should be known by the students as we can spread the knowledge to our paediatric patients. 97\% of the students are aware that herpangina shows oral manifestations. It is important for dental students to be aware of diseases that show oral lesions such as herpangina.

Regarding the management and treatment of herpangina, $53 \%$ of the students have stated that there is not antiviral therapy available for this disease and it is true. There are no drugs indicated for Evs. Broad spectrum antiviral drugs are generally given for clinical treatments Antiviral drugs such as acyclovir, ganciclovir and monosodium phosphate vidarabine should not be given to herpangina patients are they are anti-DNA viral drugs which has no effect on RNA viruses (Yu et al., 2020)However about $83 \%$ of the students have chosen antivirals as a choice of medication for herpangina. Even though a specific antiviral therapy was not found for herpangina students should not give any antivirals available. These antivirals 
have no effect on herpangina. Dental students should be made vigilant about drug prescription as it may have other effects on the patient. Better understanding of the disease will aid its treatment.

Figure 3: Pie chart shows the responses of students for the advised medication for herpangina. $87 \%$ have selected only analgesics.

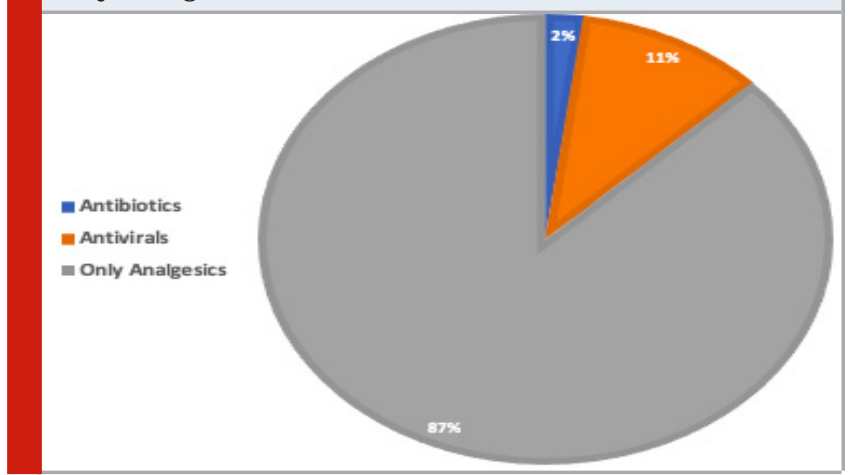

Diet plays an important role in treating herpangina and $69 \%$ of the students do believe this. The patients are advised to have a light meal, advised not to have any hot, spicy, sour, coarse, hard or irritating foods. Liquid or semi-liquid food at small frequent meals are advised. 79\% of the students believe that the use of mouthwashes aids in the treatment of herpangina. Oral care is important as herpangina has many oral manifestations. Lightly salted water or normal saline are recommended for the patients to rinse their mouths after meals(Yu et al., 2020) These maintain oral hygiene and prevent any other further oral disease and also prevent the spread of the existing disease.

\section{CONCLUSION}

Awareness of dental students can always be enhanced by promoting more educational programmes regarding various diseases such as herpangina. It is important as they will play an important role in the medical field in the future. Within the limit of the study, the overall awareness regarding herpangina and its management is good. In the future, this study can be done in a larger scope to determine the level of knowledge of students regarding herpangina

\section{ACKNOWLEDGEMENTS}

The authors are thankful to Saveetha Dental college for providing a platform to express our knowledge

Conflict of Interest: The authors declare no conflict of interest

\section{REFERENCES}

Anbu, R. T. et al. (2019) 'Comparison of the Efficacy of Three Different Bone Regeneration Materials: An Animal Study', European journal of dentistry, 13(1), pp. 22-28.

Ariga, P. et al. (2018) 'Determination of Correlation of
Width of Maxillary Anterior Teeth using Extraoral and Intraoral Factors in Indian Population: A Systematic Review', World Journal of Dentistry, 9(1), pp. 68-75.

Ashok, V. and Ganapathy, D. (2019) 'A geometrical method to classify face forms', Journal of oral biology and craniofacial research, 9(3), pp. 232-235.

Chea, S. et al. (2015) 'Workshop on use of intravenous immunoglobulin in hand, foot and mouth disease in Southeast Asia', Emerging infectious diseases, 21(1). doi: 10.3201/eid2101.140992.

Corsino, C. B. and Linklater, D. R. (2019) 'Herpangina', in StatPearls. Treasure Island (FL): StatPearls Publishing. Duraisamy, R. et al. (2019) 'Compatibility of Nonoriginal Abutments With Implants: Evaluation of Microgap at the Implant-Abutment Interface, With Original and Nonoriginal Abutments', Implant dentistry, 28(3), pp. 289-295.

Evaluation of Corrosive Behavior of Four Nickelchromium Alloys in Artificial Saliva by Cyclic Polarization Test:An in vitro Study' (2017) World Journal of Dentistry, 8(6), pp. 477-482.

Ganapathy, D. M., Kannan, A. and Venugopalan, S. (2017) 'Effect of Coated Surfaces influencing Screw Loosening in Implants: A Systematic Review and Meta-analysis', World Journal of Dentistry, 8(6), pp. 496-502.

Gupta, P., Ariga, P. and Deogade, S. C. (2018) 'Effect of Monopoly-coating Agent on the Surface Roughness of a Tissue Conditioner Subjected to Cleansing and Disinfection: A Contact Profilometric Study', Contemporary clinical dentistry, 9(Suppl 1), pp. S122S126.

Jain, A. R. (2017a) 'Clinical and Functional Outcomes of Implant Prostheses in Fibula Free Flaps', World Journal of Dentistry, 8(3), pp. 171-176.

Jain, A. R. (2017b) 'Prevalence of Partial Edentulousness and Treatment needs in Rural Population of South India', World Journal of Dentistry, 8(3), pp. 213-217.

Jiao, W. et al. (2019) 'The Effectiveness of Different Doses of Intravenous Immunoglobulin on Severe Hand, Foot and Mouth Disease: A Meta-Analysis', Medical principles and practice: international journal of the Kuwait University, Health Science Centre, 28(3), pp. 256-263.

July, A. M. J. (1998) 'Deaths among children during an outbreak of hand, foot, and mouth disease-Taiwan, Republic of China, April--July 1998', MMWR. Morbidity and mortality weekly report, 47, pp. 629-632.

Li, X.-W. et al. (2018) 'Chinese guidelines for the diagnosis and treatment of hand, foot and mouth disease (2018 edition)', World journal of pediatrics: WJP, 14(5), pp. 437-447.

Ranganathan, H., Ganapathy, D. M. and Jain, A. R. (2017) 'Cervical and Incisal Marginal Discrepancy in Ceramic Laminate Veneering Materials: A SEM Analysis', Contemporary clinical dentistry, 8(2), pp. 272-278. 
Repass, G. L., Palmer, W. C. and Stancampiano, F. F. (2014) 'Hand, foot, and mouth disease: identifying and managing an acute viral syndrome', Cleveland Clinic journal of medicine, 81(9), pp. 537-543.

Ruan, F. et al. (2011) 'Risk factors for hand, foot, and mouth disease and herpangina and the preventive effect of hand-washing, Pediatrics, 127(4), pp. e898-904.

Saoji, V. A. (2008) 'Hand, foot and mouth disease in Nagpur', Indian journal of dermatology, venereology and leprology, 74(2), pp. 133-135.

Van Heerden, W. F. P. (2006) 'Oral manifestations of viral infections', South African family practice: official journal of the South African Academy of Family Practice/Primary Care. Taylor \&t Francis, 48(8), pp. 20-24.

Varghese, S. S., Ramesh, A. and Veeraiyan, D. N. (2019)
'Blended Module-Based Teaching in Biostatistics and Research Methodology: A Retrospective Study with Postgraduate Dental Students', Journal of dental education, 83(4), pp. 445-450.

Wang, S. M. et al. (1999) 'Clinical spectrum of enterovirus 71 infection in children in southern Taiwan, with an emphasis on neurological complications', Clinical infectious diseases: an official publication of the Infectious Diseases Society of America, 29(1), pp. 184-190.

Wang, S.-M. and Liu, C.-C. (2009) 'Enterovirus 71: epidemiology, pathogenesis and management', Expert review of anti-infective therapy, 7(6), pp. 735-742.

$\mathrm{Yu}, \mathrm{H}$. et al. (2020) 'Diagnosis and treatment of herpangina: Chinese expert consensus', World journal of pediatrics: WJP, 16(2), pp. 129-134. 